Int. J. Curr. Res. Med. Sci. (2017). 3(3): 14-21

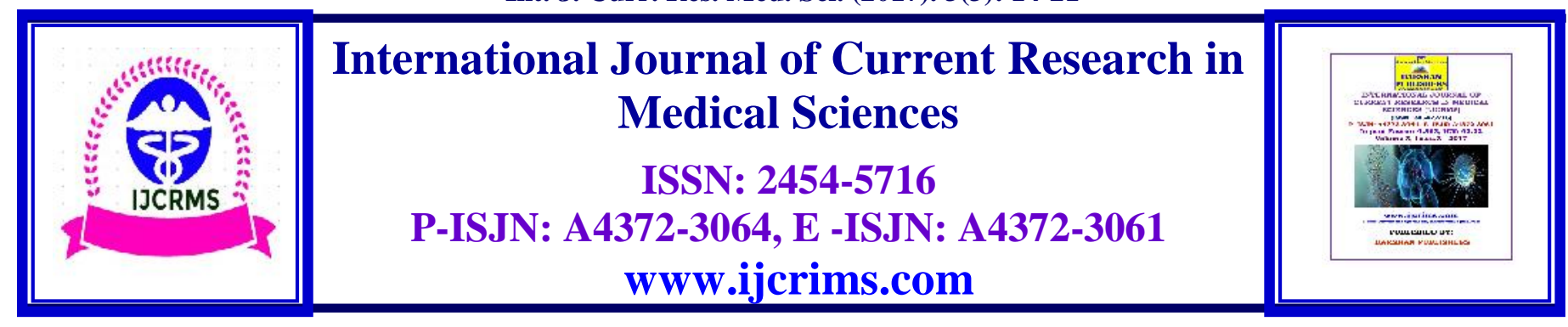

\title{
Thyroid profile in multi transfused children of beta Thalassemia major and its correlation with serum ferritin levels
}

\author{
Lham Drema*,Palwinder Singh**,Karnail Singh***,Mukhtiar singh Pannu****, \\ Manmeet Kaur**, N.S.Neki ***** \\ *Junior Resident Paediatrics, **Associate Professor Paediatrics, ***Professor Paediatrics, \\ *****Professor and Head Paediatrics, Govt. Medical College, Amritsar, 143001, India \\ ******Professor Medicine, Govt. Medical College, Amritsar, India
}

Corresponding Author: Dr. Palwinder Singh, Associate Professor, Paediatrics, Govt. Medical College, Amritsar, India

E-mail: drpalwinderrajput@gmail.com

\begin{abstract}
Background: Thalassemia major is a hereditary anemia which is caused by defective synthesis of hemoglobin, ineffective erythropoiesis and rapid erythrocyte breakdown. Transfusions in beta thalassemia major are necessary for survival of these patients. Frequent blood transfusions and inadequate iron chelation therapy can result in iron overload which may lead to various endocrine complication such as thyroid dysfunction, cardiomyopathy, diabetes mellitus, hypogonadism.

Objectives: To study the frequency of hypothyroidism in thalassemia and to study the correlation between iron overload as measured by serum ferritin levels and incidence of thyroid dysfunction, in children with thalassemia major on regular transfusion therapy.

Methods: This is a single center prospective study including 100 children attending thalassemia day care center and on regular blood transfusion therapy for a minimum of 2 years and whose ferritin level is above $1000 \mathrm{gm} / \mathrm{dl}$. Detailed history and examination were recorded in the proforma. Blood was drawn for thyroid function tests and most recent ferritin value obtained from patients record was used for analysis.

Results: Subclinical hypothyroidism was found in $24 \%$ patients and $2 \%$ had overt hypothyroidism. There was no correlation between serum ferritin levels and thyroid dysfunction.

Conclusion: Hypothyroidism was found to be a complication of thalassemia in around $26 \%$ children in our study. Detection of hypothyroidism is important as effective replacement therapy is available. Therefore, thyroid function should be followed periodically, particularly when other iron overload-associated complications occur. Early recognition and hence prevention of these complications might help improve the quality of life of these patients.
\end{abstract}

Keywords: Beta thalassemia, hypothyroidism, serum ferritin. 


\section{Introduction}

The term Thalassemia is derived from the Greek word, thalassa (sea) and haima (blood). The term "thalassemia" refers to a group of blood diseases characterized by decreased synthesis of one of the two types of polypeptide chains ( $\alpha$ or $\beta$ ) that form the normal adult human hemoglobin molecule $(\mathrm{HbA}, \alpha 2 \beta 2)$, resulting in decreased filling of the red cells with hemoglobin, and anemia ${ }^{1}$. Despite it being a preventable disease, a large number of patients continue to be born with transfusiondependent thalassemia primarily due to lack of awareness and poor access to medical facilities.

Every year around 100,000 children are born with beta thalassemia major in the world and around 10,000 are born in India alone. The carrier rate of $\beta$-thalassemia gene varies between $1-3 \%$ in south India and 5-15\% in north India.The disease was previously considered fatal before 2 nd decade of life $^{2}$. The combination of transfusion therapy and chelation therapy has dramatically extended the life expectancy of the children with $\beta$-thalassemia major who can now live into their third and fourth decades. The only curative treatment available is stem cell transplant which is not affordable in countries like India ${ }^{3}$.

Due to the lack of physiological pathway for iron excretion, frequent blood transfusions and increased intestinal iron absorption will eventually lead to iron overload ${ }^{4}$. This iron overload may lead to various complications, including various endocrinal complications such as thyroid, parathyroid, pituitary and pancreatic dysfunction etc $^{5}$.

The iron burden on the body can be estimated by means of serum ferritin, iron and TIBC levels. The estimation of serum ferritin levels is the most commonly employed test to evaluate iron overload in $\beta$-thalassemia major. The association between serum ferritin and levels of body iron are well established and the test is easy to perform compared with other tests for iron overload ${ }^{6}$.

Thyroid dysfunction is known to occur frequently in thalassemia major, but its prevalence and severity varies in different cohorts and the long- term natural history is incompletely described. The most common form of thyroid dysfunction seen in thalassemia is primary hypothyroidism. Nonetheless, the frequency of hypothyroidism shows a discrepancy depending on the region, quality of management and treatment protocols. It is a general belief that thyroid dysfunctions appear with a frequency of $13-60 \%$ in thalassemic patients after 10 years of age regardless of difference in the rate of prevalence, largely as in the form of subclinical hypothyroidism ${ }^{7}$.

In India, cost of chelation precludes ideal therapy for majority of the patients and the compliance with transfusion is often not optimal. Therefore there is a possibility that there may be high prevalence of hypothyroidism in thalassemic children. We evaluated the thyroid function tests in thalassemia major patients and correlated the results with serum ferritin level.

\section{Materials and Methods}

This prospective study was conducted on 100 children already diagnosed of $\beta$-thalassemia major attending the Thalassemia Day Care Centre, department of Pediatrics (BebeNanki Mother and Child Care Centre), Govt. Medical College and Hospital, Amritsar. Institutional Ethics Committee clearance and informed consent from the parents of all children under study was obtained. Children included in the study were children with $\beta$-thalassemia major in the age group of 3-16years who were on regular follow up at Thalassemia Day Care Centre of Govt. Medical College and Hospital, Amritsar, who had received repeated blood transfusion for atleast 2 years and whose ferritin level is above 1000 $\mathrm{gm} / \mathrm{dl}$.Data regarding age, gender, disease duration, presenting clinical features, frequency of blood transfusion, type of chelation therapy, adherence to chelation therapy, pre-transfusion $\mathrm{Hb}$ were recorded on a prescribed performa. History suggestive of hypothyroidism was obtained in detail. Detailed clinical examination of these children for any evidence of iron overload and hypothyroidism or any other associated complication was done. Blood samples for investigations were collected before blood transfusion. Thyroid function tests (T3, T4 and 
TSH) were done in all patients by ELISA method. Values of serum ferritin levels were obtained from patient's medical records and the most recent value was recorded for analysis.

According to the values of thyroid functions so obtained, patients were divided into 3 groups:

- Group I - Euthyroid: Normal T3, T4 and TSH

- Group II- Subclinical hypothyroidism: Normal T3, T4 and raised TSH

- Group III- Overt hypothyroidism: Decreased T3 or T4 and increased TSH

Results so recorded were analysed statistically using statistical software SPSS. Mean values with standard deviation were presented for continuous variables and numbers with percentages for categorical variables. P-value was considered as a parameter to assess significance of various observations and results. P-value $<0.05$ was taken as significant.

\section{Results}

Out of 100 children included in the study $72 \%$ were males and $28 \%$ were females. Mean age of the study population was $9.85 \pm 4.05$ years. Hypothyroidism was found in $28 \%$ children in the study group out of which $24 \%$ were subclinical hypothyroidism and only $2 \%$ were overt hypothyroidism.As shown in table 1 and figure 1out of 24 subclinical hypothyroid patients $16.7 \%, 16.7 \%, 37.5 \%$ and $29.1 \%$ were in the age groups 6-8years, 9-11years, 12-14years and $>14$ years respectively. None of the patients in the subclinical hypothyroid group was between 35years of age. Among the overt hypothyroid group 1 patient $(50 \%)$ was in the $12-14$ years age group and 1 patient $(50 \%)$ was in $>14$ years age group. $65.4 \%$ males and $34.6 \%$ females were hypothyroid. There were no signs and symptoms suggestive of hypothyroidism. The mean T3 and T4 were normal in the subclinical hypothyroid group but was lower in the overt hypothyroid group than the euthyroid group. Mean TSH was higher in both subclinical and overt hypothyroid group (Table 2). On statistical analysis there was a significant difference in the mean T3, T4 and TSH values of euthyroid and hypothyroid groups (Table 3).

Table 1: Thyroid profile of study population in different age groups

\begin{tabular}{|c|c|c|c|c|c|c|}
\hline \multirow{2}{*}{$\begin{array}{c}\text { Age } \\
\text { (Years) }\end{array}$} & \multicolumn{5}{|c|}{\begin{tabular}{c} 
Thyroid function groups \\
\cline { 2 - 7 }
\end{tabular}} & \multicolumn{2}{|c|}{ Euthyroid (I) } & \multicolumn{2}{c|}{$\begin{array}{c}\text { Subclinical hypothyroidism } \\
\text { (II) }\end{array}$} & Overt hypothyroidism (III) \\
\cline { 2 - 7 } & $\begin{array}{c}\text { No. of } \\
\text { patients }\end{array}$ & $\%$ & $\begin{array}{c}\text { No. of } \\
\text { patients }\end{array}$ & $\%$ & No. of \\
patients & $\%$ \\
\hline $3-5$ & 16 & 21.6 & 0 & 0 & 0 & 0 \\
\hline $6-8$ & 24 & 32.4 & 4 & 16.7 & 0 & 0 \\
\hline $9-11$ & 9 & 12.2 & 4 & 37.5 & 1 & 50 \\
\hline $12-14$ & 15 & 20.3 & 9 & 29.1 & 1 & 50 \\
\hline$>14$ & 10 & 13.5 & 7 & 100 & 2 & 100 \\
\hline Total & 74 & 100 & 24 & & & 0 \\
\hline
\end{tabular}


Figure 1: Thyroid profile of study population in different age groups

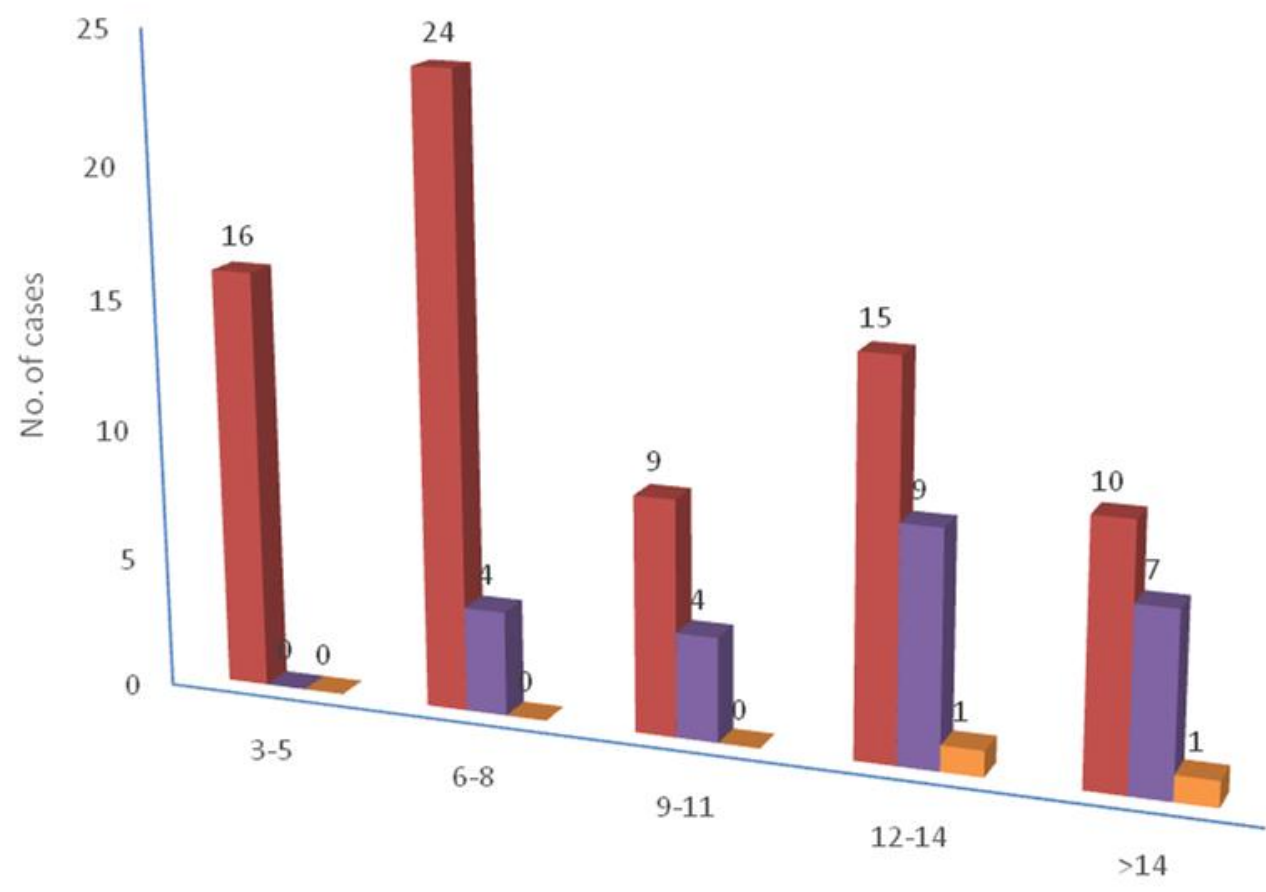

AGE GROUP (YEARS)

Euthyroid (I) Eubclinical hypothyroidism (II) $\quad$ Overt hypothyroidism (III)

Table 2: mean values of T3, T4 and TSH in different thyroid function groups

\begin{tabular}{|c|c|c|c|}
\hline Thyroid function group & T3(ng/dl) & T4 T4( g/dl) & TSH(mIU/I) \\
\hline Euthyroid (I) & $139.90 \pm 23.51$ & $7.87 \pm 2.05$ & $3.07 \pm 1.32$ \\
\hline Subclinical (II) & $136.04 \pm 24.13$ & $7.15 \pm 1.65$ & $9.35 \pm 2.59$ \\
\hline Overt hypothyroidism (III) & $87.5 \pm 5.5$ & $1.50 \pm 0.42$ & $59.96 \pm 59.96$ \\
\hline
\end{tabular}

Table 3: Comparison of thyroid functions (T3, T4, TSH) in different thyroid groups

\begin{tabular}{|c|c|c|c|}
\hline Thyroid function groups & \multicolumn{3}{|c|}{ p-value } \\
\cline { 2 - 4 } & Mean T3 & Mean T4 & Mean TSH \\
\hline Group I vs II- & 0.274 & 0.054 & $0.001^{*}$ \\
\hline Group I vs III- & $0.004^{*}$ & $0.041^{*}$ & $0.001^{*}$ \\
\hline Group II vs III- & $0.001^{*}$ & $0.005^{*}$ & $0.001^{*}$ \\
\hline
\end{tabular}

*p-value significant 
Int. J. Curr. Res. Med. Sci. (2017). 3(3): 14-21

Table 4 and figure 2 shows serum ferritin levels in different thyroid groups. There was no significant difference in the mean serum ferritin levels in different thyroid groups (Table 5).

Table 4: serum Ferritin levels in different thyroid groups

\begin{tabular}{|c|c|c|c|c|c|c|}
\hline $\begin{array}{c}\text { Serum Ferritin } \\
(\mathbf{g} / \mathbf{d l})\end{array}$ & Euthyroid & $\%$ & $\begin{array}{c}\text { Subclinical } \\
\text { hypothyroid }\end{array}$ & $\%$ & $\begin{array}{c}\text { Overt } \\
\text { hypothyroidism }\end{array}$ & $\%$ \\
\hline$<2000$ & 29 & 39.1 & 7 & 29.17 & 1 & 50 \\
\hline $2001-3000$ & 19 & 25.7 & 3 & 12.5 & 1 & 50 \\
\hline $3001-4000$ & 19 & 25.7 & 7 & 29.17 & 0 & 0 \\
\hline$>4000$ & 7 & 9.5 & 7 & 29.17 & 0 & 0 \\
\hline Total & 74 & 100 & 24 & 100 & 2 & 100 \\
\hline
\end{tabular}

Figure 2: serum Ferritin levels in different thyroid groups

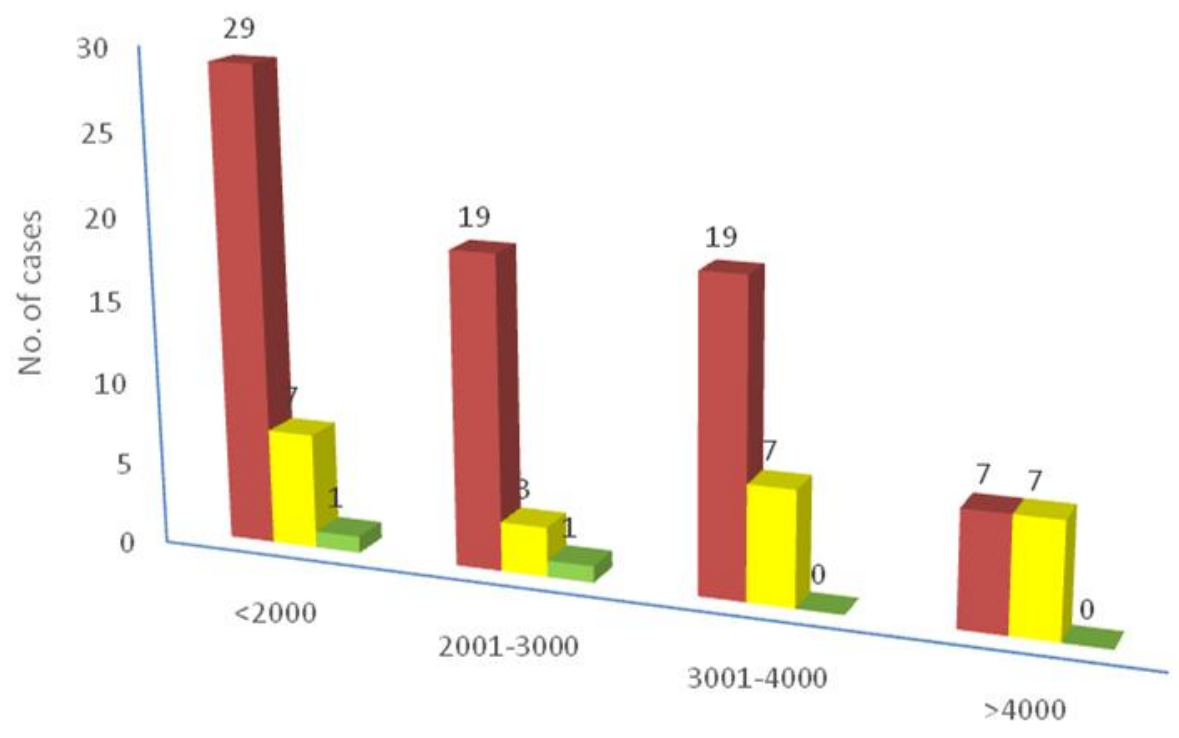

SERUM FERRITIN $(\mu \mathrm{g} / \mathrm{dl})$

- Euthyroid $\quad$ Subclinical hypothyroid $\quad$ Overt hypothyroidism

Table 5: Comparison of mean serum ferritin values between different thyroid groups

\begin{tabular}{|c|c|c|c|}
\hline Group & $\begin{array}{c}\text { Serum ferritin } \\
\text { Mean } \pm \text { SD }\end{array}$ & \multicolumn{2}{|c|}{ p -value } \\
\hline Group I (Euthyroid) & $2385.21 \pm 1894.73$ & Group I vs II & 0.102 NS \\
\hline Group II (Subclinical) & $3065.69 \pm 1194.31$ & Group II vs III & 0.407 NS \\
\hline $\begin{array}{c}\text { Group III (Overt } \\
\text { hypothyroidism) }\end{array}$ & $2219.53 \pm 338.49$ & Group I vs III & 0.902 NS \\
\hline
\end{tabular}

NS- Not Significant 


\section{Discussion}

Present study was undertaken to estimate the serum levels of total T3, T4, TSH and serum ferritin in multitransfused beta thalassemia major patients and correlation of thyroid hormone dysfunction with high serum ferritin value. In the present study, $74 \%$ of the patients were euthyroid and $26 \%$ had disturbed thyroid function. Out of the disturbed thyroid functions, isolated elevation of TSH was found in $24 \%$ of patients which was consistent with the diagnosis of subclinical hypothyroidism. Similarly, increased TSH was the most common thyroid dysfunction in previous studies conducted by Pirinççioğluet $\mathrm{al}^{7}$, Jaruratanasirikul et $\mathrm{al}^{8}$, Malik et $\mathrm{al}^{9}$, Hashemizadeh et $\mathrm{al}^{10}$ and Gathwala et $\mathrm{al}^{11}$. In the present study, $2 \%$ of the patients were having low T4 and elevated TSH, consistent with the diagnosis of overt hypothyroidism. Again this finding is comparable to the study conducted by Solankiet $\mathrm{al}^{12}$. Other workers like Malik et $\operatorname{al}^{9}(1.4 \%)$, Hashemizadeh et $\mathrm{al}^{10}(1 \%)$ found overt hypothyroidism in even lesser number of patients. This observation of thyroid dysfunction in the present study was not comparable to the findings ofCostinet $\mathrm{al}^{13}$ and Kuo et $\mathrm{al}^{14}$ as they found normal thyroid function in thalassemic patients. In the present study no evidence of clinical hypothyroidism was found but it has been reported as $6.9 \%$ by Agarwalet $\mathrm{al}^{15}, 4 \%$ by Zervas et $\mathrm{al}^{16}$ and $18.3 \%$ by Magro et $\mathrm{al}^{17}$.

In the present study, mean $\mathrm{T} 3$ and $\mathrm{T} 4$ and $\mathrm{TSH}$ values in euthyroid groups were $139.90 \pm 23.51$, $7.87 \pm 2.05,3.07 \pm 1.32$ respectively, $136.04 \pm 24.13$, $7.15 \pm 1.65,9.35 \pm 2.59$ respectively in subclinical hypothyroid group and 87.5 $\pm 5.5,1.50 \pm 0.42$, $59.96 \pm 59.96$ respectively in overt hypothyroid group. Comparison between mean values of thyroid hormones in euthyroid and hypothyroid group showed a significant difference (Table 3 ). Our results were comparable to study conducted by Agarwal et al ${ }^{15}$ who also showed a significant difference in thyroid function tests (T3, T4 and TSH) between euthyroid and hypothyroid groups.
Although serum ferritin is the most widely used test for assessment of iron status in these patients, present study did not show any statistically significant difference in mean serum ferritin level between hypothyroid and euthyroid group (Table 5).Similar observation has been replicated in previous studies by Shamshirsazet al $^{3}$, Agrawal et $\mathrm{al}^{15}$, Jaruratanasirikul et $\mathrm{al}^{8}$ and Zervas et $\mathrm{al}^{19}$. These finding suggest the possibility that single serum ferritin level alone may not be sufficient to determine the implication of chronic iron exposure in developing thyroid dysfunctions. There is no doubt that iron overload has important role to play in thyroid and other endocrinal dysfunction in thalassemic patients, insignificant difference in ferritin levels between hypothyroid and euthyroid groups in our and above mentioned studies $^{3,8,15,19}$ suggests that the damage of endocrine glands caused by chronic hypoxia due to prolonged anemia may be an associated factor responsible for thyroid dysfunction. Results contrary to present study were shown by Pirincciogluet $\mathrm{al}^{7}$ and Jaipuria et $\mathrm{al}^{20}$ who showed significant higher level of serum ferritin levels in hypothyroid group as compared to euthyroid group. However the mean age of their study population was $7.17 \pm 3.78$ years and 8.75 years respectively which was lower as compared to our study population $(9.85 \pm 4.05)$.

\section{Conclusion}

Thus it can be concluded from the present study that hypothyroidism is an important complication of $\beta$-thalassemia major patient occurring in about $26 \%$ children, although $24 \%$ patients have subclinical hypothyroidism and only $2 \%$ have overt hypothyroidism. Further, there was no direct correlation between serum ferritin and thyroid dysfunction in these patients. As many of hypothyroid patients were subclinical cases, their regular physical examination for any overt sign of hypothyroidism alongwith their periodic thyroid function assessment must be done to pick up cases of overt hypothyroidism who need replacement therapy. It is important because early 
recognition and treatment of overt hypothyroidism will definitely help to improve the quality of life of these patients especially with reference to growth and development. Further the lifelong replacement therapy for hypothyroidism is quite cheap and simple to administer.

Source of Funding: Nil

Conflict of interest: None declared

\section{References}

1. Galanello R, Origa R. Beta thalassemia. OJRD 2010; 5(11):1-15.

2. Lokeshwar MR. Progress in the management of thalassemia. Indian Pediatr 2006; 43:503-6.

3. Shamshirsaz A, Bekheirnia M, Kamgar M,Pourzahedgilani N, Bouzari N, Habibzadeh $\mathrm{M}$, et al. Metabolic and endocrinologic complications in $\beta$-thalassemia major. BMC Endocrine Disorders 2003; 3(4):1-6.

4. Cunningham MJ, Macklin EA, Neufeld EJ, Cohen AR. Complications of $\beta$-thalassemia major in North America. Blood 2004; 104: 34-9.

5. Gulati R, Bhatia V, Agarwal SS. Early onset of endocrine abnormalities in $\beta$-thalassemia major in a developing country. JPEM 2000; 13(6): 651-6.

6. Ikram N, Hassan K, Younas M, Amanat S. Ferritin Levels in patients of $\beta$-thalassemia major. IJP 2004; 2(2): 71-4.

7. PirinççioğluAG, Deniz T, Gökalp D, Beyazit N, Haspolat K, Söker M. Assessment of thyroid function in children aged 1-13 years with beta-thalassemia major. Iran $\mathrm{J}$ Pediatr 2011; 21(1):77-82.

8. Jaruratanasirikul S, Wongcharnchailert $\mathrm{M}$, Laosombat V, Sangsupavanich P, Leetanaporn K.J Med Assoc Thai 2007; 90 (9):1798-802.

9. Malik SA, Syed S, Ahmed N. Frequency of hypothyroidism in patients of betathalassaemia. J Pak Med Assoc. 2010; 60:1720.
10. HashemizadehH ,Noori R.Assessment of hypothyroidism in children with $\beta$-thalassemia major in North Eastern Iran. IJPHO 2012; 1(2): 123-7.

11. Gathwala G, Das K, Agrawal N. Thyroid hormone profile in Beta thalassemia major children .Indian J Pediatr 2009; 4(2): 20-9.

12. Solanki US, Bhargava AK, Adole PS. Assessment of thyroid function in multitransfused children of $\beta$ thalassemia major with iron overload. WJPPS 2014; 3(8): 217783.

13. Costin G, Kogut M, Hyman CB, Ortega J. Endocrine Abnormalities in Thalassaemia Major. American Journal of Diseases in Children 1979; 133(5):497-502.

14. Kuo B, Zaino E, Roginsky MS. Endocrine Function in Thalassemia Major. Journal of Clinical Endocrinology and Metabolism 1969; 28(6):805-8.

15. Agarwal MB, Shah S, Vishwanathan C, Rajadhyaksha G, Bhave AA, Dube SR, Billa V, Malkan G, Bajan K. Thyroid dysfunction in multi-transfused iron loaded thalassemia patients. Indian Pediatr. 1992 May; 29(8):997-102.

16. Zervas A, Katopodi A, Protonotariou A, Livadas S, Karagiorga M, Politis C, et al. Assessment of Thyroid Function in Two Hundred Patients with $\beta$-Thalassemia Major. 2002; 12(2): 151-4.

17. Magro S, Puzzonia P, Consarino C, Galati MC, Morgione S, Porcelli D, Grimaldi $\mathrm{S}$, Tancrè D, Arcuri V, De Santis V, et al. Hypothyroidism in patients with thalassemia syndromes.ActaHaematol. 1990; 84(2):72-6.

18. Zervas A, Katopodi A, Protonotariou A, Livadas S, Karagiorga M, Politis C, et al. Assessment of thyroid function in two hundred patients with beta-thalassemia major.Thyroid. 2002 Feb;12(2):151-4. 
19. Jaipuria R, Nigam RK, Malik R, Shrivastava A, Balani S, Tripathi A. Assessmant of thyroid function in children with $\beta$ thalassemia major and its correlation with serum ferritin and transfusion index. JEMDS 2014; 13(4): 847-54.

\begin{tabular}{|c|c|}
\hline \multicolumn{2}{|c|}{ Access this Article in Online } \\
\hline 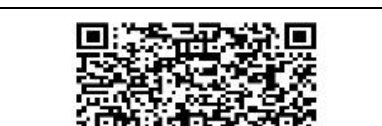 & $\begin{array}{l}\text { Website: } \\
\text { www.ijcrims.com }\end{array}$ \\
\hline 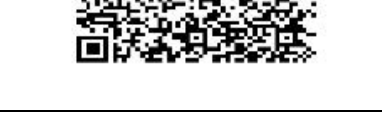 & \multirow[t]{2}{*}{$\begin{array}{l}\text { Subject: } \\
\text { Paediatrics }\end{array}$} \\
\hline Quick Response Code & \\
\hline
\end{tabular}

How to cite this article:

Lham Drema, Palwinder Singh, Karnail Singh, Mukhtiar singh Pannu, Manmeet Kaur, N.S.Neki. (2017). Thyroid profile in multi transfused children of beta Thalassemia major and its correlation with serum ferritin levels. Int. J. Curr. Res. Med. Sci. 3(3): 14-21.

DOI: http://dx.doi.org/10.22192/ijcrms.2017.03.03.003 